\title{
LA VIDA DIGNA, ACOTADA POR LA ÉTICA
}

\section{DIGNITY, WORTH LIFETIME AND ETHICS}

Ana Teresa López de Llergo

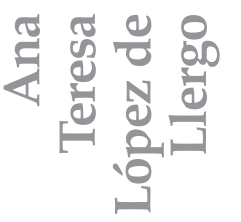

Fue subdirectora de la Escuela de Pedagogía de la Universidad Panamericana. Doctora en Ciencias de la Educación, Universidad de Navarra.

alopezde@up.edu.mx

\section{RESUMEN}

Ante planteamientos incisivos es natural que las personas -individualmente o en grupo- deseen expresar su punto de vista. Dentro de las estructuras democráticas esto se acentúa. Pero para no ir a la deriva es necesaria la explicación desde los fundamentos educativos para resolver las cuestiones de manera adecuada al alto nivel de la condición humana.

Uno de estos temas es «la vida digna». Hasta ahora el concepto está dirigido al ser humano, pero tal vez en el futuro se desee aplicar a otros, por ejemplo, a los animales domésticos, precisamente por la cercanía vital; sin embargo, tal extensión es indebida por la gran diferencia entre la vida humana y la de cualquier otra criatura.

La dignidad sólo corresponde al ser humano porque tiene espiritualidad. El punto de partida es quién y cómo es la criatura 
humana, y cómo puede ser ética su vida. Así, ya estamos en condiciones de definir la vida digna y relacionarla con la ley natural y las virtudes.

Palabras clave: criatura humana, ética, vida digna, ley natural, virtudes.

\section{ABSTRACT}

Facing incisive approaches it is natural that people -meeting with others or individually - want to say their point of view. Within democratic frames this is even emphasized.

But, for not going achievement an educational basis explanation is necessary to answer every question at the highest level of the human condition.

One of these topics is «worth lifetime». Up to now, this term is being addressed to human being, but in the future, it could as well be transferred to others like, pets, considering the vital closeness. Nevertheless, this transference is inappropriate for the great difference between human being and other creatures.

«Dignity» belongs only to human being because of to human being because of his spiritual life. Therefore, in this work the starting point is, in this work the starting point is who and how human creature is, and how who and how human creature is, and how ethic his life can be. Now, we are in condition to make a definition of worth lifetime and the natural law and virtues relationship.

Key words: human creature, ethics, worth lifetime, natural law, virtues.

\section{INTRODUCCIÓN}

Una concepción bien centrada y veraz acerca de la criatura humana es la siguiente: «Lo más perfecto que hay en toda la naturaleza, es 
decir, un sujeto subsistente en una naturaleza racional» (Aquino, 1959, I q.29 a 3).

La racionalidad consiste en la capacidad de deliberar, ponderar, elegir y actuar. Precisamente por estas operaciones se conoce la libertad intrínseca que impregna toda la actividad humana, y por eso, el marco de la vida humana está absolutamente vinculado a la ética, al dilema entre la elección del bien para una vida virtuosa, o del mal para una vida inmoral, viciosa.

Hace 26 años, Alasdair MacIntyre (1987, p. 157) predijo que la pérdida de las virtudes tiene funestas repercusiones a nivel personal y social. Las consecuencias están patentes, a la vista de todos: corrupción política y económica; falta de respeto a la vida; infidelidad como comportamiento «normal» en las relaciones personales, entre cónyuges, con la empresa o en la política; la calumnia y la mentira como patrones de conducta para conseguir fines injustos...

Hace falta volver a la moralidad de las costumbres, a procurar la virtud personal para mejorar relaciones privadas y públicas. Con gente honesta, existe la confianza en las relaciones sociales. Con personas que asumen la educación, surge el progreso. Con hombres y mujeres justos, la justicia propicia el bien común. De ahí que hoy es estrictamente necesario que todo proyecto social, cultural, político, junto con propuestas concretas sobre los respectivos asuntos, incorpore un planteamiento bien definido para recuperar la cultura de la virtud.

Pero, para lograr estas metas, es imprescindible tener un punto de partida sólido y éste consiste en la veraz comprensión de quién es el ser humano.

\section{QUÉ SE ENTIENDE POR VIDA DIGNA}

Generalmente las situaciones límite nos muestran el modo de ser de una persona; sin embargo, es preciso tener en cuenta que precisamente por tratarse de un momento extremoso, también las respuestas son exageradas, aunque ponen de manifiesto aspectos que no se mostrarían en circunstancias ordinarias. 
Refiere Álvarez del Río (2009) que Elizabeth Kübler Ross expuso su valiosa experiencia aplicada a la enseñanza, en la década de los años 60 del siglo pasado. Al hablar con 200 pacientes terminales, clasificó cinco etapas por la que ellos transitaban al conocer su estado cercano a la muerte: negación, enojo, negociación, depresión y aceptación.

Ante sucesos especiales en la vida de cada persona, es importante enfrentarse a las respuestas que cada uno ha de dar a ciertas preguntas, como: ¿qué significa este suceso, cómo lo puedo afrontar, con quién y con qué medios?... Siempre situarse ante la realidad para afrontarla es un adelanto; aunque resulte costosa y las respuestas sean insatisfactorias, al menos ya se ha superado la tendencia a evadir y a escudarse en ensueños con los cuales no se resuelve algo y sí se complican los problemas, pues crecen al retrasar la solución.

Para el desarrollo personal, el ejercicio de la libertad es imprescindible. Esto es, la capacidad de elegir en cada momento, de aceptar las condiciones de la vida, así, es más fácil dar sentido a los sucesos. Cada persona ha de reorientar su vida y prever los siguientes capítulos, aún inéditos.

Entre las múltiples expresiones humanas, existe una donde se manifiesta la necesidad de recubrirse, de adornarse, de exaltarse, como reflejo del sentimiento de superioridad. Se trata de la decoración corporal. Pero, a pesar de la necesidad de aparecer bien, existe algo más íntimo y es la necesidad de ser bien. Taylor (1994, p. 65) lo expresa de esta manera:

Ésta es la poderosa idea moral que ha llegado hasta nosotros. Atribuye una importancia moral crucial a una suerte de contacto con uno mismo, con mi propia naturaleza interior, que considera en peligro de perderse, debido en parte a las presiones para ajustarse a la conformidad exterior; pero también porque, al adoptar una posición instrumental conmigo mismo, puedo haber perdido la capacidad de escuchar esta voz interior. $Y$ esto hace aumentar la importancia de este contacto con uno mismo introduciendo el principio de originalidad: cada una de nuestras voces tiene algo propio que decir. No sólo no debería plegar mi vida a las exigencias de la conformidad exterior; ni siquiera puedo encontrar fuera de mí, el modelo conforme al que vivir. Sólo puedo encontrarlo en mi interior. 
La persona se desarrolla al actualizar todo el potencial interno, por medio del equilibrio armonioso entre el esfuerzo personal - conocimiento de la ley natural, formación de la conciencia, reflexión, toma de decisiones y actuación con evaluación moral de lo realizado-y las influencias externas —educación familiar, escolar y social- Un desajuste entre estos ámbitos puede ocasionar la falta de identidad, con las consecuencias de planteamientos extremos como el cambio de sexo; o posturas exageradas de autoafirmación con diversos niveles de agresividad, que ocasionan conductas antisociables.

En la siguiente tabla se sintetiza el proceso de desarrollo y el modo de realizarlo:

\begin{tabular}{|l|l|l|l|l|l|}
\hline $\begin{array}{l}\text { Referentes } \\
\text { externos }\end{array}$ & $\begin{array}{l}\text { Proceso } \\
\text { interior }\end{array}$ & $\begin{array}{l}\text { Desarrollo de } \\
\text { autoidentidad }\end{array}$ & $\begin{array}{l}\text { Sociedades } \\
\text { primitivas }\end{array}$ & $\begin{array}{l}\text { En anomía } \\
\text { social }\end{array}$ & $\begin{array}{l}\text { Con } \\
\text { psicopatología }\end{array}$ \\
\hline Sociedad & $\begin{array}{l}\text { Auto } \\
\text { identidad }\end{array}$ & $\begin{array}{l}\text { Ubicación } \\
\text { asumida }\end{array}$ & $\begin{array}{l}\text { Normas } \\
\text { tribales } \\
\text { suministardos }\end{array}$ & Antisocial & Anómala \\
\hline Amistades & $\begin{array}{l}\text { Auto } \\
\text { conciencia }\end{array}$ & Auto reflexión & $\begin{array}{l}\text { Normas } \\
\text { tribales }\end{array}$ & Marginación & $\begin{array}{l}\text { Eeficienciánea } \\
\text { estructural }\end{array}$ \\
\hline Educación & Carácter & Maduración & Crecimiento & $\begin{array}{l}\text { Crecimiento } \\
\text { defectuoso }\end{array}$ & Inmadurez \\
\hline Familia & Temperamento & Herencia & Herencia & Herencia & $\begin{array}{l}\text { Herencia e } \\
\text { influencia } \\
\text { anómala }\end{array}$ \\
\hline
\end{tabular}

Elaboración propia con base en Medina, Moreno, Lillo y Romero (2004, pp.5-13).

Los referentes externos se han agrupado en cuatro rubros: la familia o entorno más cercano e íntimo, la educación formal e informal, las amistades donde se manifiestan las preferencias personales y la sociedad en donde se prestan servicios laborales y existe participación ciudadana. 
El proceso interior de desarrollo parte del temperamento, entendido como la herencia recibida de los progenitores; ella es la materia básica donde se recibe la educación y hay un modelaje que, al madurar, produce el carácter. Con la experiencia de las relaciones humanas, la persona reflexiona y toma conciencia de sí misma, madurando su grado de conocimiento personal. La multitud de relaciones sociales ubica a la persona y define su personalidad. Por eso, la columna del desarrollo de la auto identidad expone el proceso deseado.

Las otras tres columnas reproducen la estructura de las sociedades primitivas, muy escasas en la actualidad aunque, como aún las hay, conviene tenerlas en cuenta para la integración de las personas que provienen de ellas, y requieren de una ayuda específica para adaptarlas a las sociedades contemporáneas. La columna de anomía social muestra la influencia externa inconveniente; en la columna de la psicopatología, el problema para el adecuado desarrollo proviene de un desajuste interior.

Por eso, para lograr el auténtico desarrollo es preciso saber el tipo de problema y su etiología para afrontarlo debidamente.

Entonces, la vida digna es aquélla donde se explayan los mejores aspectos del ser humano, tanto en su dimensión personal como en la social. Sin embargo, el marco de referencia de esos aspectos es la ley natural.

\section{LA ÉTICA COMO UNA VÍA PARA CONSEGUIR LA VIDA DIGNA}

Nuestra experiencia, y también nuestra aprehensión intelectual de la persona - en y a través de sus acciones-, se deriva en especial del hecho de que las acciones poseen un valor moral: son moralmente buenas o moralmente malas. La moralidad constituye un rasgo intrínseco y lo que se puede considerar como su perfil específico, algo que no se da en una actuación que presuponga un agente que no sea persona. 
Este texto de Karol Wojtyla (2000, p. 13) nos recuerda la realidad de que toda actividad humana está teñida por la moral, nada es neutro. La base de toda moralidad radica en la ley natural, de allí la necesidad, en el contexto actual, de propiciar en la cultura y en la sociedad civil y política las condiciones indispensables para una plena conciencia de la responsabilidad de hacer el bien y evitar el mal.

La ley natural es la ley de la moralidad inscrita en lo más íntimo de cada persona. Todo ser humano encierra en sí un mensaje moral y una indicación para los caminos de la justicia social. La ley natural excluye del relativismo o del reduccionismo ideológico, garantiza el buen uso de la libertad y el respeto de la dignidad de toda persona. Además evita cualquier manipulación ideológica o cualquier abuso. De este modo se facilita la inclinación natural al desarrollo perfectivo propio del ser humano virtuoso.

El Catecismo de la Iglesia Católica (1992, p. 435) en el número 1954 señala:

La ley natural expresa el sentido moral original que permite al hombre discernir mediante la razón lo que son el bien y el mal, la verdad y la mentira.

En definitiva, los diez mandamientos. En el número 1956 (p. 436) añade:

La ley natural, presente en el corazón de todo hombre y establecida por la razón, es universal en sus preceptos, y su autoridad se extiende a todos los hombres. Expresa la dignidad de la persona y determina la base de sus derechos y sus deberes fundamentales.

La palabra areté, que llegó más tarde a ser traducida por virtud, se usa en los poemas homéricos para la excelencia de cualquier clase; un corredor veloz exhibe la areté de sus pies (Ilíada 20,411) y un hijo aventaja a su padre en cualquier tipo de areté, como atleta, soldado y en cacumen (Ilíada 15, 642). Este concepto de virtud o excelencia nos es más ajeno de lo que a primera vista logramos advertir. No nos es 
difícil darnos cuenta del lugar central que la fuerza tendrá en una tal concepción de la excelencia humana, como se citó en Macintyre (1987, p. 157).

Precisamente porque en el ser humano existe esa tendencia a lo mejor, es posible lograrla. Ello supone la aceptación personal y libre de cada uno para comprometerse con el propio desarrollo, aunque también es necesario procurar un ambiente sano que facilite esos deseos. Actualmente, esa dimensión social se ha descuidado; hace falta una unión de voluntades para limpiar el entorno y facilitar el ejercicio de las virtudes.

Por lo tanto, la virtud es un hábito, una cualidad que depende de nuestra voluntad, consistiendo en este medio que hace relación a nosotros y que está regulado por la razón en la forma que lo regularía el hombre verdaderamente sabio. Aristóteles (1980, p. 69).

Hoy, en el mundo contemporáneo hacen falta personas ejemplares comprometidas con el desarrollo de los demás.

\section{CONCLUSIONES PRÁCTICAS}

La vida digna requiere un ritual, tanto para el ser humano que lo vive, como para los demás que son tratados como personas, y es necesario redescubrir el valor de la ley moral natural para colocar los cimientos de la necesaria ética comprometida con la adquisición personal de las virtudes.

En primer lugar, es esencial afrontar la realidad de ser miembro de una sociedad y asumir el compromiso de mejorar las relaciones interpersonales, ayudando a la mejora de cada uno, empezando por lo propio. Al asumir la libertad se asegura la supervivencia de las instituciones: familiares, laborales, etcétera. Todo esto es posible con el ejercicio de la virtud de la veracidad y de la fortaleza para reconocer lo que a cada quien le falta y esforzarse por adquirirlo. 
La colaboración llevará a una postura abierta y esperanzada frente al futuro, porque nadie sufrirá el dolor de la soledad y se sumarán esfuerzos. Cuando varias personas se unen para el bien, es más fácil afrontar los problemas sin evadirlos. La fuerza de uno al sumarse con la de otros, crece de manera exponencial. También es un modo de compartir experiencias y volverse expertos. En esta actitud, crecen la virtud de la humildad para aceptar la ayuda mutua, y la paciencia para adecuarse al ritmo de los demás.

Cuando se lucha por metas comunes, el beneficio es muy grande: se aprende a valorar al otro, se propicia la apertura a distintos grados de amistad. La claridad de alguien puede ser luz y sacar de las tinieblas a otro que estaba dudoso o desorientado. Se cultiva el amor de benevolencia, fruto de la virtud de la caridad.

Así, se construye una sociedad en donde se fomente la virtud de la fidelidad, que abre a la capacidad de asumir cualquier tipo de compromiso. Además, la virtud de la prudencia cultiva la vigilancia amable para evitar dar malos ejemplos. Por eso, también se pueden orientar, con vigor, los contenidos de los medios de difusión y de entretenimiento, aplicando la fortaleza para no dejarse llevar por lo fácil.

Sanear el ambiente no será utópico, y las costumbres facilitarán la buena elección de amistades, los modos de diversión y el recto ejercicio laboral.

La construcción de la cultura no puede ser exclusivamente material, es necesario incluir la dimensión espiritual, con la inclusión de lo religioso. La trascendencia sobrenatural eleva la realidad natural. Sólo el respeto a Dios hace sólida la ley moral.

Las crisis -imprescindibles en el camino del desarrollo- serán oportunidades de mejora, de rectificación del rumbo, de evaluación de las decisiones y, en muchos momentos, motivo para recomenzar por caminos inéditos. Toda crisis puede tener una lectura positiva, pues evitará caer en los mismos errores, abrirá nuevas opciones, ambientará nuevos escenarios. Así, se mantiene vivo el espíritu joven y emprendedor. 
Por último, viene bien la consideración de que abrirse al otro no mutila la propia personalidad, por el contrario, fomenta la vida virtuosa propia y la del otro, eso redundará en el beneficio del «nosotros».

Abrirse a la comprensión produce un enriquecimiento inmenso, aunque de primera instancia suponga sacrificio. Cuando alguien pasa por un momento especialmente difícil, es más fácil superar la negación, el enojo, y la depresión para negociar y aceptar. Quienes nos rodean también nos ayudan con el buen ejemplo, su compañía y comprensión. Las relaciones humanas mejoran cuando se cuenta con otro semejante.

\section{REFERENCIAS}

Álvarez del Río, Asunción. El médico ante el sufrimiento del paciente. Revista de Investigación Clínica, Vol. 61, N. 2, Marzo-Abril, 2009, pp. 173-180.

Aristóteles. Moral a Nicómaco, $7^{\mathrm{a}}$ edición, Espasa Calpe, México, 1980.

Catecismo de la Iglesia Católica. Librería Juan Pablo II, República Dominicana, 1992.

De Aquino, Tomás. Suma Teológica, BAC, Madrid, 1959.

Macintyre, Alasdair. Tras la virtud, Editorial Crítica, Grijalvo, Barcelona, 1987.

Medina, A.; Moreno, Ma. J.; Medina, I.; Lillo, R. y Romero, J. Por qué decoramos nuestro cuerpo. Revista Monografías de Dermatología, Vol. XVII, No. 6, Noviembre-Diciembre, 2004, pp. 5-13.

Taylor, Charles. La ética de la autenticidad, Paidós Ibérica S.A., Barcelona, 1994.

Wojtyla, Karol. Persona y acción, BAC, Madrid, 2007. 